\title{
$\mathbf{X I}$
}

\section{PANDEMIA, SAÚDE MENTAL E DROGAS: AS VIDAS PRECÁRIAS COMO QUESTÃO NO SERVIÇO SOCIAL*}

\author{
Marco José de Oliveira Duarte \\ Carolina Morais Simões de Melo \\ Marcela Mendes Sales \\ Thays Ribeiro da Silva
}

\section{Introdução}

\begin{abstract}
La pandemia del COVID-19 ha venido a develar lo que ya sabíamos: una desigualdad social impresionante con sus racismos, sexismos, heterosexismos y empobrecimiento. Devela además que la acumulación capitalista es un sistema de muerte. A pesar de que el COVID afectó a la gente europea, va afectar más a la gente de Abya Yala y de África, porque hace tiempos que nuestros sistemas de salud son precarios y privatizados, porque la gente no aguanta el confinamiento porque debe salir a buscar que comer cada día. Tenemos aproximadamente un $80 \%$ de mercado informal en la región. En todo eso, los gobiernos van a priorizar el mercado y no salvar vidas, mucho menos aquellas vidas que aun no se consideran suficientemente humanas, como la gente empobrecida que en general es negra e indígena, como está pasando en muchos países, sobre todo en Brasil (CURIEL, 2020, p. 276).
\end{abstract}

Escrevemos esse texto em um momento particular da história mundial, principalmente, quando a Organização Mundial da Saúde (OMS) declarou, em 30 de janeiro de 2020, que o surto da doença causada pelo novo coronavírus (SARS-CoV-2), que causa a COVID-19, constitui uma Emergência de Saúde Pública de Importância Internacional. Em 11 de março de 2020, a COVID-19 foi caracterizada pela OMS como uma pandemia, transmitida de pessoa para pessoa, que pode se manifestar em infeç̧ões assintomáticas em sua maioria (80\%), oligossintomáticas (poucos sintomas) a quadros graves, levando a óbito. Nesse universo, em todo o mundo, aproximadamente,

*DOI- 10.29388/978-65-86678-44-4-0-f.279-308 
$20 \%$ dos casos detectados requer atendimento hospitalar por apresentarem dificuldade respiratória, dos quais aproximadamente $5 \%$ podem necessitar de suporte ventilatório em centros ou unidades de tratamento intensivo $(\mathrm{CTI})^{1}$. Mas, infelizmente, uma parcela significativa tem morrido, independente do enquadramento epidemiológico de grupo de risco, termo superado nos tempos de pandemia da AIDS.

Segundo dados da OMS, no mundo, registra-se hoje ${ }^{2}$ 28.268.970 casos infectados, 19.048 .042 casos recuperados e 911.282 mortes. O Brasil, particularmente, apresenta 4.282 .164 casos, 3.530.655 casos recuperados e 130.396 mortes, localizando-se em segundo lugar no ranking mundial, abaixo apenas dos Estados Unidos da América, em número de casos e mortes. Não à-toa, ambos os países são dirigidos por forças neoconservadoras, expressos nas narrativas de extrema-direita, com "desdemocratização neoliberal" (BROWN, 2015, p. 77) ou como nos afirma Casara (2018), um Estado pós-democrático, além do forte conteúdo explícito de ódio, mostrando sua política racista, xenofóbica, classista, heterossexista, LGBTfóbica e neofascista, que revela sua necropolítica (MBEMBE, 2018) à maioria da população.

Desta forma, o vírus não afeta a todos da mesma forma, é um simulacro o seu efeito democrático (CALMON, 2020). Ele afeta em cheio a classe trabalhadora e, em particular, quando interseccional, ao gênero feminino e a raça negra. Nesse sentido, os reflexos da pandemia atingem em cheio, acentuando com maior radicalidade as desigualdades sociais, com mais vulnerabilidades e precariedades às condições de vida e trabalho dos sujeitos dessa classe. Como afirma Harvey (2020a, p. 16) "o impacto econômico e demográfico da disseminação do vírus depende de fissuras e vulnerabilidades preexistentes no modelo econômico hegemônico".

Portanto, a crise não é só sanitária, no Brasil, quando se pensa na estrutura e lógica do capital. A crise capitalista se articula as crises política, moral e econômica e a pandemia tem forçado a queda da so-

\footnotetext{
${ }^{1}$ Mais informações desses dados no site da World Health Organization (WHO) - Organização Mundial da Saúde, disponível em: <https://apps.who.int/iris/handle/10665/333114>. Acesso em: 10 set.2020.

${ }^{2}$ Dados coletados e disponível em: <https://news.google.com/covid19/map?hl=pt-BR\&mid= \%2Fm\%2F01hd4s\&gl=BR\&ceid=BR\%3Apt-419>. Aceso em: 10 set. 2020.
} 
brevivência da maioria da população brasileira, mas em particular aos/as negros e negras, que tenta estruturar sua existência social, econômica, política e subjetiva, frente ao aumento exorbitante da taxa de desemprego, ao perverso genocídio da juventude negra, a cruel exposição ao vírus e, consequentemente, a doença, sem as mínimas condições de saúde, de habitação, de saneamento, dentre outras expressões da "questão social" que a conjuntura real e concreta nos apresenta de forma mais perversa, radical, racista e a céu aberto (DUARTE et al, 2020).

Assim, tomar o campo da saúde mental e drogas, pelo olhar do Serviço Social, enquanto profissão e área de conhecimento, no contexto da pandemia da COVID-19, a partir do seu aporte teóricometodológico e do pensamento social crítico contemporâneo, é analisar criticamente, pelo víeis das determinações sócio-históricas e na perspectiva da totalidade das relações sociais capitalistas, as precariedades das vidas (BUTLER, 2019), dos corpos, dos trabalhos e dos territórios dos sujeitos sócio-históricos.

Desta forma, nossa tessitura analítica se dá pela interseccionalidade de classe, gênero, raça, trabalho, moradia, transporte, território e saúde. Tomando os efeitos nocivos e perversos desse processo pandêmico em curso e de como o Estado brasileiro vem agindo frente a essa questão, que afeta diretamente a classe trabalhadora e seus modos de existência e resistência como um todo, acentuando mais ainda as desigualdades sociais, como a pobreza, o desemprego, o racismo e a precarização cada vez maior da vida singular e coletiva da maioria da população brasileira.

\section{Pandemia e determinantes sociais da saúde: A precarieda- de dos corpos e territórios}

Em 2020 o mundo se viu diante de um fenômeno minimamente inesperado, que, além de nos colocar diante dos processos de saúde-doença e dos dilemas da vida e da morte, nos colocou diante de questões básicas de sociabilidade humana, como a inevitável coexistência humana mundializada, as relações sociais no modelo de (re)produção e urbanização vigentes e as noções de liberdade e ética. 
Se é fato que o COVID-19 tem uma alta taxa de contaminação e de letalidade, com todos seus determinantes biomédicos, é possível perceber que essa doença não é tão democrática quanto se tenta mostrar nos noticiários. Diante da mundialização da economia, da ampla circulação de produtos e pessoas em escala global e da interconexão dos territórios, não é possível falar de adoecimento e de cuidado em saúde sem considerar os determinantes sociais desse processo e como se relacionam intimamente aos territórios em que este vírus circula, se instala e mata.

De forma mais fundamental, os seres humanos não são autossuficientes, visto que a respiração é um direito humano que só pode se efetivar graças a outros seres. Portanto, "pensar a contaminação, proliferação e propagação da COVID-19 é pensar espacialmente" (MEDEIROS, 2020, p. 143), e pensar em espaço é compreendê-lo como um organismo vivo, e não como uma superfície ou um território inerte.

O espaço é o "produto de uma multiplicidade de trajetórias" (MASSEY, 2004; 2015 apud MEDEIROS, 2020, p. 144), de forma que o controle do espaço passa pelo controle dessa multiplicidade, revelando a interdependência e coabitação de diversas trajetórias individuais em uma coletiva. Assim, "o espaço como dimensão em que encontros acontecem é também a esfera na qual outras possibilidades de vida e morte podem se tecer" (MEDEIROS, 2020, p. 145).

$\mathrm{O}$ alastramento do vírus tem instigado estratégias de controle dos espaços através do controle das trajetórias individuais, porém, de forma desigual e parcial. Se por um lado há um esforço de limitação da circulação pelo território em nome da saúde e da vida, este não inclui toda a população, excluindo aquela responsável pela manutenção mais básica das nossas vidas cotidianas. Há também quem se negue a ter sua circulação pelo espaço controlada, e clamam pela reabertura dos comércios e instituições ou violam as normas de contenção da doença, em nome do retorno a um estado de "normalidade" questionável e segregacionista, onde os riscos de contágio e morte não atingem seus proponentes. Nesse sentido é que se coloca a discussão ética do entrelaçamento inevitável de nossas trajetórias, indicando que viver espacialmente está diretamente relacionado com o princípio de liberdade. 
Viver o princípio da liberdade [...] é viver espacialmente. Por vezes, liberdade e espacialidade se conjugam de maneira esquisita. Em tempos de pandemia, liberdade não é ir onde se quer, na hora em que se deseja, e provavelmente nunca tenha sido, mas um modo de responder eticamente ao espaço, isto é, considerando que em nossas trajetórias residem outras vidas (MEDEIROS, 2020, p. 146-147).

César Simoni (2020) afirma que, "se o vírus causador da pandemia tivesse um DNA, ele traria o gene da sociedade urbana" (SIMONI, 2020, p. 25), o que pode ser visto por sua profilaxia ser definida mais no âmbito social e urbano do que no âmbito da biomedicina. $\mathrm{O}$ autor remete ao conceito de sociedade urbana, definida por Lefebvre como "o encontro, a concentração e a centralidade" (SIMONI, 2020, p. 25) que definem a forma de sociabilidade edificada no século XX.

É no espaço urbano que ocorrem as trocas, tanto do comércio quanto de todo metabolismo social e biológico. São as características de proximidade, vizinhança e convívio que caracterizam a noção de aglomeração, gerando uma certa solidariedade involuntária, onde "os diferentes se encontram, os contrários se tocam, os trabalhos se completam e a vida se compartilha" (SIMONI, 2020, p. 26). Essas formas de encontro, aglomeração e concentração, no processo de modernização, tornaram-se servas da acumulação de riquezas, de forma que o urbano concentra tanto a riqueza quando a pobreza ao mesmo tempo. Assim, "é o sentido e o fundamento da vida urbana que são postos em questão diante das medidas sanitárias que impõem o distanciamento físico e a separação dos corpos" (SIMONI, 2020, p. 26).

É importante não perder de vista os determinantes políticoeconômicos mais gerais que estão em andamento, gerando impactos significativos para a classe trabalhadora, sendo uma configuração da "questão social" contemporânea, voltando nossa atenção à fase atual de acumulação do capital. A pandemia do coronavírus, longe de ser a responsável pela calamidade pela qual passamos, revela e aprofunda as contradições do capitalismo neoliberal de nosso século, associado com a ascensão das políticas antidemocráticas (BROWN, 2019).

A acumulação impõe uma aceleração, uma pulsão econômica com fins de alcançar incessantemente os lucros, o que tem afetado neste contexto de pandemia principalmente os espaços da pobreza. 
Simoni indica que a COVID-19 se dissemina através de uma "dispersão socialmente orientada: uma dispersão geográfica, mais do que geométrica" (SIMONI, 2020, p.27), em que há um padrão socioespacial com um corte de classe, sendo os pobres suas principais vítimas.

Simoni analisa a cartografia de óbitos e de casos confirmados pela COVID-19 no município de São Paulo, indicando que a doença chegou a partir das áreas do município com maiores vínculos internacionais, mas, a partir do deslocamento e do fluxo de trabalhadores pela cidade, a doença "encontrou nas periferias e nos espaços de pobreza um ambiente muito mais favorável à sua disseminação" (SIMONI, 2020, p. 32). Há um maior número de notificações de casos confirmados nas áreas mais ricas de São Paulo, porém o maior número de notificações de mortes está na periferia, o que indica que há, minimamente, uma subnotificação de casos confirmados da doença nas periferias, bem como que o vírus mata mais nessas áreas.

Jorge Luiza Barbosa e Lino Teixeira (2020) realizaram análise semelhante na cidade do Rio de Janeiro, encontrando a mesma tendência de dispersão espacial da doença para os espaços de pobreza. Analisaram os casos confirmados e os óbitos na cidade do Rio de Janeiro nos meses de março, abril e maio, apontando uma rápida expansão geográfica da doença nos subúrbios, favelas e periferias cariocas. Ainda que pese a subnotificação, é possível perceber que os bairros que concentram as favelas cariocas possuem menores taxas de notificações de casos confirmados e as maiores taxas de notificação dos óbitos em comparação com outras regiões, levando-os a identificar que "a taxa de letalidade de cada Zona da cidade acompanha em maior ou menor grau as condições socioeconômicas reveladoras das desigualdades urbanas." (BARBOSA; TEIXEIRA, 2020, p. 71) . $^{3}$

Essa perspectiva aponta para o fato de que as nossas periferias vitimadas pelo espírito non stop da ganância econômica, pela situação de permanente urgência vivida pelas suas populações, pelo caos promovido pelas fake News, pela falta de condições sanitárias adequadas, entre tantas outras coisas, talvez, silenciosamente, estejam se

\footnotetext{
${ }^{3}$ Os autores indicam que essa dinâmica espacial do município do Rio de Janeiro se assemeIha à dinâmica dos municípios de Fortaleza, Manaus, Recife, Salvador e São Paulo (BARBOSA; TEIXEIRA, 2020).
} 
tornando verdadeiros barris de pólvora pandêmicos (SIMONI, 2020, p. 32).

Não é possível analisar os impactos do novo coronavírus sem nos atentar para a sua disseminação geográfica, que aponta para as desigualdades territoriais, e para o modo de vida e de relações urbanas capitalistas, que revelam as desvantagens que uma parte da população vivencia, excluída não só do direito à saúde, mas também do direito à cidade.

A aversão ao tempo lento e a precariedade impiedosamente rentável das condições de trabalho, combinadas ao novo ingrediente virulento, converteram a forma do encontro e da aglomeração em um reprovável e potente sistema urbano de contaminação verde e amarelo. O que resta do urbano em tempos de pandemia capitalista por aqui é oferecido sem chance de recusa aos condenados pelo mundo do trabalho: eis o avesso do direito à cidade (SIMONI, 2020, p. 34).

A territorialização das doenças nas áreas pobres das cidades não é uma novidade na discussão dos determinantes sociais de saúde da população brasileira, sendo um indicador de agravo de várias doenças e condições de saúde da população. Isso se insere em uma lógica mais ampla, que tem guiado o Estado nas medidas de prevenção às doenças e promoção de saúde e, particularmente, aquelas de combate ao novo coronavírus.

Danilo Volochko (2020) considera que o capitalismo em sua fase atual toma contornos por vezes fascistas e atualiza o neomalthusianismo, a biopolítica e gera uma lógica de morte. Chama de neomalthusianismo a atualização da teoria malthusiana, que considerava que a causa da pobreza era o crescimento da população, sendo necessário, consequentemente, um controle de natalidade. Essas ideias convergem com os conceitos de biopolítica e biopoder, trabalhados por Michel Foucault (2005; 2008a; 2008b), que apontam para o controle dos corpos pelo Estado, representando dominação e poder, expressas em características fundamentais do homem: nascimentos, mortes e doenças. Assim, Volochko (2020) ao se aproximar também do conceito de necropolítica (MBEMBE, 2018), indica que "nesta demografia do capital, nesta demografia de um Estado, de uma econo- 
mia e de uma sociedade neoliberais, nesta que é uma demografia de classes, uns podem e devem morrer mais do que outros" (VOLOCHKO, 2020, p. 37).

Esse ajuste demográfico do capital foi chamado pelo autor por necrodemografia, ou seja,

[...] a demografia da morte a orientar as políticas de nosso Estado atualmente, significando o sacrifício necessário de vidas de trabalhadores pobres para que o capital saia vivo da enorme crise provocada pelo isolamento social e pela paralisação geral de diversos setores produtivos durante a pandemia. Se a tragédia brasileira antecede à pandemia, com a precarização do trabalho elevada à precarização da vida, parece não bastar mais apenas a precarização da vida, sendo necessária a eliminação de vidas daqueles que não têm condições sociais, urbanas, econômicas, dos favelados, dos trabalhadores informais moradores de periferias, para salvar o capital (VOLOCHKO, 2020, p. 39).

David Harvey completa essa equação com mais alguns determinantes importantes: "o progresso da COVID-19 exibe todas as características de uma pandemia de classe, de gênero e de raça" (HARVEY, 2020b). Dessa forma, é preciso compreender a relação que existe entre os corpos e os territórios que estes ocupam, que corpos são estes e como suas singularidades interferem em suas vidas - e em suas mortes.

As relações raciais estruturam a desigualdade, a precariedade e a vulnerabilidade dos territórios. É nesse sentido que Barbosa e Teixeira (2020) apontam, a partir dos dados do Instituto Brasileiro de Geografia e Estatística (IBGE), de 2019, que 75\% dos brasileiros que vivem na extrema pobreza (renda per capita inferior a $R \$ 145,00$ ) são pretos e pardos (negros) e estes formam dois terços dos 12 milhões de trabalhadores desempregados. Isso significa que o acesso dessa população à água e saneamento básico adequados, saúde e aos itens de desinfecção, estão totalmente comprometidos.

Além disso, destaca-se a dificuldade ao apelo do isolamento social devido tanto à alta concentração de pessoas nas periferias e favelas, bem como a necessidade de circular pela cidade para manter seus postos de trabalho. Agrava-se o quadro se considerarmos que as doenças crônicas que são riscos à saúde e à vida em comorbidade 
com a COVID-19, como hipertensão e diabetes, são potencializadas de acordo com as condições de vida, como a ingestão de alimentação inadequada e bebidas alcoólicas. Todos esses elementos, essenciais para a proteção contra o novo coronavírus, não fazem parte da vida desses sujeitos, indicando uma relação intrínseca entre pobreza e raça no Brasil, sendo a raça ou etnia um importante determinante social de saúde em nosso país.

Herbert Santos et. al. (2020) discutem a importância da variável racial na análise dos dados epidemiológicos sobre as infecções pelo SARS-Cov-2 nas regiões brasileiras, indicando como a inclusão ou ausência deste dado manifesta-se como mecanismo da necropolítica e produtor de iniquidades em saúde. A primeira indicação do autor é pela ausência de registros claros da raça de pacientes infectados ou mortos pela COVID-19, indicando que invisibilizar os dados sobre raça/cor formatam e endossam a necropolítica, invisibiliza as mortes e o adoecimento desigual de pessoas negras. Acrescenta que essa é uma negligência intencional do enfrentamento da pandemia pelo Estado, baseado no racismo estrutural e institucionalizado, que, em sua política de morte contra negros, não se limita à saúde.

\footnotetext{
Afinal de contas, o que se percebe dentro de uma estrutura de um sistema que legitima mortes de pessoas negras são as diversas articulações tanto no sistema penal que encarcera, quanto na violência policial que aniquila, quanto na saúde pública que invisibiliza suas mortes. Resta nítido que a necropolítica funciona perfeitamente bem no Brasil (SANTOS et al., 2020, p. 01).
}

A pandemia também atinge de forma desigual as mulheres, revelando sua expressão de gênero, que nada mais é do que o agravamento das condições de vulnerabilidade que já vivem em seu cotidiano. Com o início pandemia, foi possível perceber nos noticiários e nos meios de denúncia um aumento dos casos de violência e de violência doméstica (MARQUES et al., 2020).

As autoras indicam, através de estudo realizado sobre os índices de violência doméstica contra mulheres, crianças e adolescentes, que é possível perceber um aumento desses índices em diversos países, como China, Reino Unido, Estados Unidos, França e Brasil (MARQUES et al., 2020). Esse quadro pode ser agravado pela menor visibi- 
lidade em decorrência do isolamento social e pelo fechamento ou horário reduzido dos serviços de proteção (delegacia de mulheres, conselho tutelar etc.).

Também é possível observar uma maior sobrecarga sobre as mulheres no contexto da pandemia. Pesquisa da startup Gênero e Número, em parceria com a Sempreviva Organização Feminista (FERREIRA; LEÃO; FERRARI, 2020), ouviu mais de 2,6 mil mulheres brasileiras entre os meses de abril e maio de 2020, por meio de questionário on-line. Dessas, $41 \%$ afirmam trabalhar mais durante a quarentena e uma média de $50 \%$ relataram serem as responsáveis pelos cuidados de outra pessoa, variando esses dados de acordo com a raça e moradia em zona rural: $52 \%$ entre as mulheres negras, $46 \%$ entre as brancas e $50 \%$ entre as indígenas ou amarelas, ressaltando que a sobrecarga é maior para mulheres negras, que têm menos suporte nas tarefas de cuidado; na zona rural, $62 \%$ das mulheres passaram a exercer tarefas de cuidado após a pandemia. Dessa forma, as mulheres acabam sendo responsáveis pelos cuidados da casa, dos filhos e, quando empregadas, dedicarem-se ao trabalho, seja externo ou teletrabalho.

O relatório da pesquisa acima também indica que as mulheres estão trabalhando mais na quarentena, sendo $55 \%$ delas brancas e $44 \%$ negras. Apesar de atingir todas as mulheres trabalhadoras, a maior parcela das mulheres que conseguiram continuar trabalhando na pandemia é de brancas, pois essas concluíram o nível superior e estão na faixa dos 30 anos, sendo uma faixa privilegiada. Importante apontar que as relações entre o trabalho e as atividades doméstica são muito imbricadas, e esse cenário se agrava por não haver ainda uma divisão equânime nas tarefas domésticas entre todos os membros da casa.

Por fim, fica evidente que todas condições de vida e trabalho da maioria da população neste contexto de pandemia da COVID-19, explicitadas acima, gera, nos dizeres de Sandra Caponi (2020), um enorme custo subjetivo e uma sensação coletiva de desamparo social, com a sensação de que cada um terá que cuidar de si, já que nos vemos sem as redes de proteção, apoio e informações confiáveis. Também aumentam o uso prejudicial de álcool e outras drogas, o 
sentimento de medo, solidão, impotência, abandono e tristeza, gerando um sentimento generalizado de fracasso coletivo.

\begin{abstract}
Em tempos de pandemia é normal ter medo da morte, é normal sentir-se angustiado perante a falta de cuidado de um Estado que abandonou seus cidadãos a sua sorte, é normal sentir raiva e impotência quando observamos que são as comunidades pobres, os negros e indígenas os que mais morrem em um país absurdamente desigual, enfim, é normal que sintamos uma tristeza profunda quando observamos que a cifra de 1000 mortos por dia foi naturalizada. Patologizar essas reações normais perante um contexto tão adverso como o que estamos vivenciando e tratar esses supostos transtornos com mais antidepressivos ou ansiolíticos, certamente terá sérias consequências biopolíticas para todos e todas (CAPONI, 2020, p. 01).
\end{abstract}

\title{
Pandemia e o mundo do trabalho: As vidas precárias no capitalismo atual
}

As mudanças mais recentes no mundo do trabalho evidenciaram as atrocidades do modo de produção capitalista contra a classe trabalhadora mundialmente. As transformações na morfologia do trabalho submeteram os trabalhadores a novos tipos de exploração, parte de uma incessante tendência do capital em precarizar as relações de trabalho. A crise intensificada pela pandemia demonstrou aos desacreditados a capacidade do capital em aniquilar vidas humanas.

Vimos grandes transformações na forma como se organiza o trabalho, que, desde o final da década de 1970, apontam para um novo tipo de trabalhador (ANTUNES, 2020). Novas modalidades de organização do trabalho foram introduzidas: terceirização, pejotização, contratos intermitentes, contratos de zero horas, uberização e a intensificação da informalidade, além do crescimento exponencial de trabalhadores autônomos, os chamados "proletários-de-si-mesmo" (ANTUNES, 2018, p. 34). O trabalho na contemporaneidade imprimiu à vida cotidiana um novo ritmo. $\mathrm{O}$ trabalhador deve estar conectado com a nova realidade do mundo do trabalho; são agora infoproletários, o trabalhador uberizado, submetidos às piores condições de trabalho. $O$ tempo fora do trabalho já quase não existe. É a vida em fun- 
ção do trabalho para atender à sede de lucro do capital. Esse novo perfil de trabalho acarretou maiores níveis de adoecimento, depressões e suicídios. Antes de estourar a crise trazida pela COVID-19, a classe trabalhadora brasileira já estava vivenciando uma série de ataques às suas condições de reprodução da vida, como a reforma trabalhista vigente desde novembro de 2017, a reforma da previdência e o congelamento dos gastos estatais.

Crises econômicas e políticas se sucedem desde antes do golpe que tirou Dilma Rousseff do governo, inserindo o governo golpista de Temer até o mais recente governo Bolsonaro, que, em poucos meses, intensificou o movimento da destruição dos direitos dos trabaIhadores com uma sequência de reformas e promoveu a efervescência de um pensamento conservador e retrógrado.

Pouco antes de se vivenciar a crise gerada pela pandemia, a classe trabalhadora já se encontrava em uma realidade degradante. Segundo a Pesquisa de Orçamentos Familiares (POF) 2017-2018, realizada pelo IBGE (2019), 16,7 milhões de domicílios viviam com até dois salários mínimos em uma realidade precarizada de trabalho. Uma vida de incertezas, oscilando entre emprego, subemprego e desemprego. Segundo dados da Pesquisa Nacional por Amostra de Domicílio - PNAD (IBGE, 2020), a informalidade, que inclui trabalhadores sem carteira assinada, prestadores de serviços sem Cadastro $\mathrm{Na-}$ cional de Pessoas Jurídicas (CNPJ), trabalhadores por conta própria sem CNPJ e trabalhadores domésticos sem carteira, atingiu $41,1 \%$ da população ocupada no ano de 2019 , o equivalente a 38,4 milhões de pessoas.

Soma-se a essa realidade a situação ainda mais precária de condição de trabalho de uma grande parcela da população brasileira, os subutilizados. Esses são os que trabalham menos de 40 horas semanais em um emprego ou, no conjunto de seus trabalhos, não alcançam uma renda estável e mínima para sobreviver, podendo estar disponíveis para outros trabalhos e que somam 23,0\% (IBGE, 2020). No entanto, desagregando esses dados, a taxa de subutilização sobe para $33,2 \%$ entre mulheres negras, atinge $22,3 \%$ entre homens negros, $20,7 \%$ entre mulheres brancas e chega a $14,2 \%$ entre homens brancos (IBGE, 2020). Ou seja, estes dados apontam para uma realidade histórica das condições de trabalho no país. Entre os trabalha- 
dores há uma parcela que se encontra em situações de trabalho ainda mais precárias e como vimos, tem raça e gênero.

A Organização Mundial do Trabalho (OIT) estimou que a pandemia durante o segundo trimestre de 2020 causaria a perda de cerca de 400 milhões de empregos, com um corte maior acontecendo nas Américas, regiões mais afetadas no momento pelo vírus e com maior número de medidas de restrição ao trabalho, com destaque para os Estados Unidos da América e Brasil, onde há um número expressivo de casos (ILO, 2020).

O crescente número de casos de pessoas contaminadas e mortes pela COVID-19 demonstrou a incapacidade do governo brasileiro em criar mecanismos para combater o vírus. Em meio a ataques aos diretos dos trabalhadores, o governo federal lançou uma série de medidas para tentar amenizar os impactos nas relações de trabalho, mas que se mostraram insuficientes, como a medida provisória que flexibilizou leis trabalhistas e permitiu a redução de salários e a suspensão do contrato de trabalho (CAVALLINI, 2020)

O auxílio emergencial foi implementado um mês após a chegada do vírus no país depois de atrasos e recuos do governo. A rede pública de saúde já estava sobrecarregada e os trabalhadores já vinham sofrendo com os impactos nos empregos e condições de trabaIho. $\mathrm{O}$ auxílio foi definido com o valor de $\mathrm{R} \$ 600,00$ por três meses e prorrogado por mais dois meses e, recentemente, por mais quatro meses, tendo seu valor reduzido para $\mathrm{R} \$ 300,00$, com a possibilidade de exclusão de 22 milhões de beneficiários (SUTTO, 2020).

No segundo trimestre de 2020, segundo dados da PNAD (IBGE, 2020), havia no Brasil cerca de 173 milhões de pessoas em idade de trabalhar e, no mesmo período, 29,1\% estavam em situação de desemprego, insuficiência de horas trabalhadas e na força de trabaIho em potencial. São um total de 12,8 milhões de pessoas sem trabalho e, entre os ocupados, 36,9\% estão na informalidade, ou seja, nos setores de trabalho mais inseguros. Dados divulgados pelo IBGE (2020) mostram que, entre os ocupados, aproximadamente 4,3 miIhões estavam afastados do trabalho devido ao distanciamento social. Cerca de 17,7 milhões gostariam de trabalhar, mas não procuraram emprego por causa da pandemia. Os trabalhadores mais impactados devido às restrições impostas pela quarentena foram os dos 
serviços, comércio e construção civil. Houve também grande impacto no setor de saúde e da limpeza. A renda média dos trabalhadores do setor privado sem carteira assinada, trabalhadores domésticos e trabalhadores por conta própria não chegou a dois salários mínimos no segundo trimestre de 2020 de acordo com a PNAD (IBGE, 2020). Esses dados demonstram o quanto a crise econômica e política, intensificada pela pandemia, agravou a já precária condição de vida e de trabalho da classe trabalhadora brasileira que, sem o auxílio emergencial, poderia estar em situações ainda mais subumanas.

Pesquisas da Fundação Getúlio Vargas (BÔAS, 2020; AUXÍLIO, 2020) demonstraram, inclusive, que o auxílio emergencial reduziu o nível de extrema pobreza e significou um aumento na renda de parcelas de trabalhadores. No entanto, isto apenas reforça o quadro de extrema e radical desigualdade social da população brasileira, que, historicamente, enfrenta baixos salários e retrocessos em seus direitos.

Os setores que não pararam, como saúde, limpeza, transporte, alimentação e energia, tiveram as condições de trabalho pioradas durante a pandemia, submetendo os trabalhadores a maiores jornadas e expondo-os à contaminação pelo vírus. São os trabalhadores que precisam se locomover, que circulam em espaços coletivos, que usam transporte público e que não possuem acessos a serviços de saúde de qualidade que estão sendo contaminados pelo vírus e morrendo. Entre os trabalhadores contaminados, aqueles com menor escolaridade foram os que mais morreram. Segundo uma matéria da Agência Senado, de agosto de 2020, 71\% dos trabalhadores infectados sem ensino fundamental faleceram enquanto, entre aqueles com ensino superior, o índice cai para 23\% (OLIVEIRA, 2020).

Na cidade de São Paulo, segundo matéria da Folha de São Paulo, de setembro de 2020 (RODRIGUES, 2020), as mortes pela COVID-19 são mais frequentes entre profissionais autônomos do que entre profissionais liberais e empregadores. Também na cidade de São Paulo, uma pesquisa conduzida pela prefeitura (PAULO, SANTIAGO, 2020) apontou que o vírus contaminou mais quem trabalha fora de casa do que os trabalhadores em home office. Entre o primeiro grupo, $18,5 \%$ contraíram a doença, já no segundo grupo, a taxa foi de $6,2 \%$. No hospital das clínicas de São Paulo, um inquérito sorológico 
(MACHADO, 2020) revelou que $45 \%$ dos trabalhadores da limpeza, lavanderia e segurança foram infectados. Já os médicos que têm contato direto com pacientes contaminados, apenas $6 \%$ deles foram diagnosticados com a COVID-19.

Em Belo Horizonte, a prefeitura informou em seu boletim epidemiológico de 23 de julho de 2020 (RONAN, 2020) que, dentre os 417 óbitos, 249 eram de pessoas pretas e pardas (59,7\% do total). Entre os infectados, $42,7 \%$ são pretos e pardos e $33,2 \%$ são brancos. Todos os dados relacionados nesse período da pandemia revelam como a realidade brasileira é profundamente desigual e, consequentemente, a classe trabalhadora é cada vez mais precarizada e alvo da política de morte do Estado com suas vidas expostas às doenças.

\section{Pandemia e políticas de saúde mental e drogas: A desde- mocracia neoliberal no contexto brasileiro}

A crise capitalista que atingiu o mundo a partir de 2008 provocou, em diversos países, a reorganização das forças políticas que disputam hegemonia no cenário transnacional. Desde então, gradativamente, vem ocorrendo um deslocamento de poder e de centralidade narrativa, que saltou das formas até então "democráticas" neoliberais de gestão política (mas também nefastas) para as experiências antidemocráticas, autoritárias e alinhadas com o neofascismo, as quais abrem mão de disfarces e escancaram as reais faces do capitalismo atual.

As práticas governamentais de caráter autoritário são gestadas justamente no âmago das crises político-econômicas graves quando a população não encontra respostas nem representantes para as suas demandas, configurando, então, um cenário alarmante de falta de representatividade política, que dá espaço para a aparição de supostas soluções práticas antidemocráticas (DORNELLES, 2020).

Dessa maneira, as crises econômica, política e social que vem marcando o início do século XXI tem sido um espaço profícuo para emergência de governos autoritários que embasados no medo, na desesperança em relação ao futuro e no ódio ao diferente, tocam adiante uma agenda de retrocessos com o argumento da necessida- 
de de sacrifícios da parte da população para reconstrução da harmonia social e do crescimento econômico.

Tal colocação é imprescindível para melhor compreendermos a recente tendência de remanicomialização no campo da atenção psicossocial que vem ocorrendo a partir de 2010, quando o Brasil começou a ver grupos conservadores ganharem força e considerável apoio populacional em diversos âmbitos político-sociais, dentre eles o campo da atenção psicossocial (DUARTE, 2018).

Desde 2010, segundo Duarte (2018) se tornou destaque, no país, a chamada "epidemia do crack", termo difundido pela mídia e grupos conservadores que traziam o discurso de necessidade de internação (voluntária ou não) dos usuários desta substância em hospitais psiquiátricos ou comunidades terapêuticas. Neste período, segundo Guimarães e Rosa (2019), a disputa pelo financiamento público na área se tornou central e a ideia de impossibilidade de tratar das questões relativas ao uso de drogas sem recorrer inicialmente à internação ganhou destaque e apoio popular.

A partir deste ano, o governo federal iniciou a construção de um aparato institucional para responder a esta suposta necessidade de internação, o que apareceu oficialmente no "Plano Integrado de Enfrentamento ao Crack e outras Drogas" e posteriormente no "Crack, é possível vencer" que assegurou certo investimento na RAPS, mas também passou a financiar leitos em comunidades terapêuticas, demarcando o avanço do conservadorismo neste campo.

Desde então é possível identificar o avanço gradativo das forças conservadoras por dentro do próprio Estado, refletidas pelos caminhos traçados para responder às demandas sociais latentes. Isto se evidencia pela existência e manutenção do que Dornelles (2020) denomina de "estado de exceção permanente" como também pelas novas formas de precarização do trabalho, subfinanciamento de políticas públicas, pela progressiva privatização da coisa pública, crescimento no índice de violência nas áreas periféricas dos grandes centros urbanos, entre outras coisas.

De acordo com Dornelles (2020), o que se viu a partir da crise econômica capitalista ora descrita foi o enorme crescimento da miserabilidade, a expansão das diversas formas de intolerância, o ultranacionalismo como bandeira política e o grande capital lançando mão 
de estratégias de dominação política através de seus representantes partidários na tentativa de fragilização das formas democráticas de disputa com intuito de manutenção do estado de exceção.

\begin{abstract}
A nova razão do mundo neoliberal e a sua nova subjetividade criaram uma racionalidade (a)democrática ou (des)democrática através da destruição ou neutralização das categorias e instituições da democracia liberal. Com isso, estão dadas as condições para estado de exceção permanente, para as novas formas de tirania do mercado, para o necrocapitalismo de barbárie e para a necropolítica (DORNELLES, 2020, p. 95).
\end{abstract}

Assim, desde 2016, com os retrocessos políticos ocorridos a partir do processo de impeachment arquitetado para destituição de Dilma Rousseff do poder executivo, o Brasil vem observando o aumento das formas precarizadas de existência humana, permeadas pela violência, pela pobreza e marcadas pela inacessibilidade às políticas sociais e públicas fundamentais para sua sobrevivência, principalmente, em tempos de autoritarismo.

Durante o governo de Michel Temer, entre os anos de 2016 e 2018, os planos mais imediatos e possíveis dos capitalistas foram executados com êxito e celeridade, como, por exemplo: a reforma trabaIhista (BRASIL, 2017) mais recente, que foi aprovada retirando direitos históricos e fundamentais dos trabalhadores; uma "nova" política de saúde mental, álcool e outras drogas (BRASIL, 2017) foi lançada sem a participação popular e respondendo aos interesses de grupos empresariais conservadores e manicomiais; foi aprovada, ainda, a Emenda Constitucional № 95/2016 (BRASIL, 2016) que congela por vinte anos o teto dos gastos com políticas sociais e afeta diretamente a área da saúde, entre outras medidas.

No campo da saúde mental, álcool e outras drogas, esse período vem se caracterizando pela desconstrução massiva dos avanços alcançados ao longo das décadas anteriores, com fundo público sendo direcionado em grande parte para o financiamento das comunidades terapêuticas, redução das verbas específicas para os CAPS, estímulo à expansão de leitos psiquiátricos, apoio à indústria farmacêutica através do incentivo à lógica medicamentosa e hospitalar, além da alteração da política sobre drogas retirando a centralidade do cuida- 
do a partir da redução de danos e priorizando a abstemia como forma de tratamento (DUARTE et al., 2020).

Como se pôde identificar, a crise econômica instaurada há anos possibilitou a ascensão ao poder de forças autoritárias, reacionárias e antidemocráticas em diversos pontos do globo, muitos em países latino-americanos, dentre eles o Brasil, que testemunhou em 2018 a conjugação entre direita neoliberal tradicional e direita ultraliberal neoconservadora para atingir objetivos ainda não alcançados durante os governos anteriores.

Dentre as ações do governo de Jair Bolsonaro que confirmam o espraiamento da ideologia conservadora e privatista de gestão da coisa pública, destacamos a alteração da Política Nacional sobre Drogas (BRASIL, 2019), que afeta diretamente o campo da atenção psicossocial. Tal política já apresentava caráter proibicionista, o que fica ilustrado pelo seu histórico de comunhão com as diversas convenções internacionais que objetivavam alcançar o controle da produção, distribuição, comercialização e consumo pela via da repressão militarizada (FONSECA; BASTOS, 2005). Contudo, no atual governo ela passou a ter aspectos ainda mais conservadores, buscando a eliminação absoluta do uso de drogas na sociedade brasileira, privilegiando as comunidades terapêuticas como locais de acolhimento para usuários, além de focar ainda mais na repressão ao tráfico de drogas.

Outra medida imposta ainda no primeiro ano do governo Bolsonaro que impacta negativamente no campo da atenção psicossocial foi a sanção da Lei 13.840 (BRASIL, 2019), que trata da internação involuntária das pessoas que fazem uso prejudicial de álcool e outras drogas sem a autorização judiciária. A referida lei autoriza que a internação dessas pessoas possa ser realizada por profissionais da área da saúde e assistência social, reforçando mais uma vez a lógica manicomial que privilegia a internação em detrimento dos demais recursos terapêuticos ofertados pelos dispositivos de saúde territoriais.

Recentemente, o Conselho Nacional de Políticas sobre Drogas (CONAD) aprovou, ainda, a regulamentação do acolhimento de adolescentes usuários de drogas em comunidades terapêuticas, indo na contramão dos avanços obtidos pela luta antimanicomial e violando direitos garantidos pelo Estatuto da Criança e do Adolescente (BRASIL, 1990). 
Portanto, com Bolsonaro ocupando o cargo de Presidente da República do Brasil, as condições socioeconômicas e sanitárias se agravaram exponencialmente durante o período da pandemia. Isso se deu tanto porque o presidente manteve uma retórica negacionista em relação à gravidade da doença e dos elevados níveis de contágio no país, o que incentivava e/ou forçava os trabalhadores a se exporem ao vírus para manter seu sustento, quanto porque a taxa de desemprego nacional subiu nos últimos meses em consequência da falta de amparo do Estado para garantir a manutenção dos postos de trabalho existentes anteriormente.

Assim, o atual presidente vem mantendo uma conduta altamente irresponsável e descompromissada com a vida da população brasileira, chegando ao ponto de até mesmo seus aliados de base governamental e ministros da saúde serem demitidos por tentarem seguir, mesmo que a partir de seus olhares típicos de empresários do ramo da saúde, os protocolos básicos estabelecidos pela OMS.

Entretanto, tais ações não se mostram tão surpreendentes, uma vez que o Estado brasileiro, antes mesmo da instauração da situação de pandemia pela OMS, já vinha afirmando uma postura conservadora, ultraliberal e antidemocrática que trazia impactos negativos no custeamento das políticas sociais e na vida propriamente dita dos sujeitos que moram em territórios marcados pela violência e pela ausência de políticas públicas que garantam seus direitos.

Esses mesmos territórios marcados pela precariedade das políticas sociais e pela ação violenta do Estado, principalmente, no que tange à chamada "guerra às drogas", são compostos, majoritariamente, por pessoas negras e trabalhadoras e trabalhadores que sofrem com as consequências da estrutura histórica do racismo brasileiro e que, atualmente, estão em situação de maior vulnerabilidade social e alto risco de contaminação pelo coronavírus.

Assim, sob a fórmula de um governo conservador e ultraliberal, o Estado vem estabelecendo a gerência das vidas da população, de acordo com pressupostos biopolíticos, que determinam quais delas são passíveis de morte e quais são merecedoras de continuar vivendo, de modo que o alto índice de mortalidade em decorrência do coronavírus correspondente aos moradores de periferias das grandes cidades e dos povos originários, não se tornando uma preocupação 
urgente, tampouco se torna alvo de ações eficientes para a diminuição do contágio.

É nessa medida que se identifica que a regulação coletiva das vidas ocorre a partir da organização da diversidade humana segundo seus marcadores sociais de diferença, como comportamentos, grau de escolaridade, raça, gênero, sexualidade, território de moradia, vinculação a determinada cultura, faixa etária etc. Desse modo, tal classificação se dá por segmentos populacionais, os quais passam a serem afetados pelas ações do Estado de maneira desigual e hierarquizada de acordo com o grupo ao qual pertencem (LEMOS et al., 2017).

Destarte, a pandemia descortinou o processo político que vem determinando quais grupos/pessoas tem direito à vida e quais podem ser exterminados, seja pela ação direta do Estado através das incursões policiais cotidianas justificadas, na maioria das vezes, pelo jargão da "guerra às drogas" ou pela inércia estatal que não produz políticas públicas para os segmentos mais vulneráveis. Portanto, a ação direta ou a inatividade do poder público corresponde ao fazer viver e deixar morrer, à defesa de certas vidas e negligência de tantas outras avaliadas como não merecedoras de existência.

Tais considerações indubitavelmente dizem respeito também ao campo da atenção psicossocial justamente porque os sujeitos assistidos, desde os tempos de Philippe Pinel até a atual crise sanitária mundial, têm seus corpos e vidas controlados pelo saber-poder médico em confluência com o poder do Estado, numa vinculação histórica que implica subalternidade e desvalorização dessas pessoas que, em sua maioria, são negras, com histórias singulares marcadas pela violência e/ou negligência do poder público, sujeitos desencaixados do padrão social com vidas precarizadas e pertencentes a territórios periféricos.

Acerca das formas de controle sobre a vida humana, Mbembe (2018) considera a existência de uma política de Estado capaz de determinar a vida e a morte de grupos bastante específicos, a necropolítica, que atua como controle da vida humana e o Estado, portanto, se configura como detentor do poder de decisão sobre quem vive e quem morre, de acordo com critérios morais de avaliação que julgam quais grupos têm sua existência supérflua, passível de extermínio e compreendida como desnecessária. 
Essa política de morte constitui-se, então, como a negação da vida na sua amplitude, operando na prática a partir da retirada de direitos basilares e destruição de políticas públicas que promovam cidadania, impossibilitando, portanto, a existência dos sujeitos na sua diversidade e singularidade.

$\mathrm{Na}$ esteira desse pensamento, Dornelles (2020) explica que a atual forma de existência e organização do capital e das relações sociais que sob ele se dão evidencia a essência capitalista opressiva, predatória, forjada pela barbárie e fundamentada na morte de grupos considerados descartáveis. Esse seria o necrocapitalismo, que conjuga a capacidade de produzir lucratividade a partir de e apesar da morte em paralelo a um posicionamento do Estado que a desconsidera enquanto um dado concreto com potencial norteador de ações em tempos de crise sanitária mundial.

Assim sendo, necropolítica e necrocapitalismo vem operando numa confluência cruel ditada por governos autoritários e, atualmente, evidenciadas pelo contexto de pandemia que tem exposto a desigualdade social e econômica, através do racismo, elitismo e discriminação de todo e qualquer diferente que compõem a história desse País, incluindo os ditos loucos, e degenerados de toda sorte, particularmente, dos que fazem uso prejudicial de drogas em contexto mais radical do proibicionismo no Estado brasileiro.

\section{Considerações finais}

A análise empreendida neste capítulo tentou levar em consideração os diversos contextos que estão diretamente impondo mais precariedade às condições de vida e trabalho do conjunto da classe trabalhadora em sua apreensão interseccional com outros marcadores sociais de diferença em tempos de pandemia. Em uma conjuntura marcada pelas crises sanitária, política, econômica e social, que, particularmente, é determinada pela nova fase da crise estrutural do capital, que se iniciou em 2008, afetando e ampliando a precarização do trabalho em escala global, mais, principalmente, frente à ascensão, nos últimos anos, de políticas antidemocráticas, com forte conteúdo neoconservador, ultraliberal e de extrema-direita que fazem do 
racismo de Estado, o gestor da política de morte às populações negras e pobres.

A pandemia exacerbou em nosso tempo histórico as relações conflitantes e degradantes entre capital e trabalho. Vivencia-se ritmos de trabalho cada vez mais acelerados: redução cada vez maior de direitos, crescente insegurança e o aumento dos riscos de morte e adoecimento. Entretanto, houve muitos protestos e enfrentamentos contra essa situação. Os trabalhadores não estão calados. Entre as várias manifestações e lutas, chama a atenção para o movimento dos entregadores de aplicativos, que, durante a pandemia, realizaram duas grandes paralisações contra a exploração e a falta de direitos dos uberizados.

Nesse contexto, inclui-se os trabalhadores do setor de saúde na defesa do Sistema Único de Saúde público e universal, incessantemente, nesse momento, na luta por acesso a medicamentos, equipamentos de proteção individual (EPI) e pelo pagamento dos seus salários. Assim como os professores e estudantes da educação pública, que enfrentam também os cortes de verbas e os ataques da extrema direita contra o ensino público, de qualidade, laico, socialmente referenciado.

Em um contexto de razão neoliberal e de desdemocratização, o Estado brasileiro, frente a pandemia, reforça sua política de austeridade e mantém "o máximo possível os mecanismos do capital, ainda que a natureza do risco os obrigue a modificar o estilo e as ações do poder" (BADIOU, 2020, p. 39). Assim, contraditoriamente, o governo federal tenta, aparentemente, "socorrer" o SUS, para o atendimento às populações infectadas, mas subordinando a saúde à lógica do mercado e do lucro, e, particularmente, é a indústria farmacêutica quem mais aparece. Nesse aspecto, em particular, ressalta-se alguns elementos: o uso de medicamentos, sem comprovação científica, contra a COVID-19, propagado de forma enganosa pelo executivo federal; o aumento de psicodiagnósticos e com isso a divulgação, prescrição e consumo de psicofármacos e por fim, o novo ordenamento geopolítico no mercado internacional que envolve as grandes multinacionais farmacêuticas na produção da vacina anti-COVID-19 e seus nacionalismos sanitários (DENTICO, 2020). 
Tempos de medicalização, farmacologização e imperialismo sanitário (CAMARGO JR, 2013) dispositivos da biopolítica, em contexto neoliberal, que oculta as determinações sociais da saúde. Por certo, em breve, corre-se o risco, no campo da saúde mental, de se ter uma massa de diagnosticados com transtornos mentais que fazem uso prejudicial de drogas psiquiátricas com sérios efeitos colaterais, além da tutela da clínica médica e da própria epidemiologia que foca na culpabilização individual pelos adoecimentos, riscos e cuidados. Apesar de todo esse processo social e complexo, a resistência é possível e a disputa de projetos políticos de sociedade, em termos de gestão da vida, é uma aposta que se opera em redes e agenciamentos coletivos.

\section{Referências}

ANTUNES, R. 0 privilégio da servidão. São Paulo: Boitempo, 2018.

. Coronavírus: o trabalho sob fogo cruzado. São Paulo: Boitempo, 2020.

AUXÍLIO Emergencial representa aumento de $24 \%$ na renda dos trabalhadores, diz estudo. G1, Rio de Janeiro, Economia, 30 de julho de 2020. Disponível em: <https://g1.globo.com/economia/noticia/ 2020/07/30/auxilio-emergencial-representa-aumento-de-24percentna-renda-dos-trabalhadores-diz-estudo.ghtml>. Acesso em: 05 set. 2020.

BADIOU, A. Sobre a situação epidêmica. In: DAVIS, M. et al. Coronavírus e a luta de classes. Terra sem Amos: Brasil, 2020.

BARBOSA, J. L; TEIXEIRA, L. Territórios populares entre as desigualdades profundas e o direito à vida. In: CARLOS, A. F. A. (Org.). COVID-19 e a crise urbana [recurso eletrônico]. São Paulo: FFLCH/USP, 2020.

BOAS, B. V. Auxílio reduz extrema pobreza ao menor nível em 40 anos, diz Ibre/FGV. Valor Econômico, Rio de Janeiro, 28 de junho de 2020. Disponível em: <https://valor.globo.com/brasil/noticia/ 2020/07/28/auxilio-reduz-extrema-pobreza-ao-menor-nivel-em-40anos-diz-ibre-fgv.ghtml>. Acesso em: 05 set. 2020. 
BRASIL. Presidência da República. Secretaria Geral. Lei Federal $\mathrm{N}^{\circ} 13.840$, de 5 de junho de 2019. Dispõe sobre o Sistema Nacional de Políticas Públicas sobre Drogas e as condições de atenção aos usuários ou dependentes de drogas e trata do financiamento das políticas sobre drogas. Diário Oficial da União. Brasília, DF, 6 jun. 2019, seção 1, p. 2.

. Presidência da República. Secretaria Geral. Decreto Federal $\mathrm{N}^{\circ}$. 9.761, de 11 de abril de 2019. Aprova a Política Nacional sobre Drogas. Diário Oficial da União. Brasília, DF, 11 abr. 2019, ed. 70-A, seção 1, Extra, p. 7.

. Ministério da Saúde. Portaria GM/MS N³.588, de 21 de dezembro de 2017. Altera as Portarias de Consolidação $n^{\circ} 3$ e no 6, de 28 de setembro de 2017, para dispor sobre a Rede de Atenção Psicossocial, e dá outras providências. Diário Oficial da União. Brasília, DF, 22 jan. 2018, seção 1, p. 46.

. Presidência da República. Secretaria Geral. Lei Federal № 13.467, de 13 de julho de 2017. Altera a Consolidação das Leis do Trabalho (CLT) a fim de adequar a legislação às novas relações de trabaIho. Diário Oficial da União. Brasília, DF, 14 jul. 2017, seção 1, p. 1.

. Presidência da República. Casa Civil. Emenda Constitucional № 95, de 15 de dezembro de 2016. Altera o Ato das Disposições Constitucionais Transitórias, para instituir o Novo Regime Fiscal, e dá outras providências. Diário Oficial da União. Brasília, DF, 15 dez. 2016, seção 1, p. 2.

. Presidência da República. Casa Civil. Lei N 8.069, de 13 de julho de 1990. Dispõe sobre o Estatuto da Criança e do Adolescente e dá outras providências. Diário Oficial da União. Brasília, DF, 16 jul. 1990, seção 1, p.13563.

BROWN, W. Nas ruínas do neoliberalismo: A ascensão da política antidemocrática no ocidente. São Paulo: Editora Filosófica Politeia, 2019.

BROWN, W. Undoing the demos: neoliberalism's stealth revolution. New York: Zone books, 2015. 
BUTLER, J. Vidas precárias: os poderes do luto e da violência. Belo Horizonte: Autêntica Editora, 2019.

CALMON, T. V. L. As condições objetivas para o enfrentamento ao COVID-19: abismo social brasileiro, o racismo e as perspectivas de desenvolvimento social como determinantes. NAU Social, Salvador, v. 11, n. 20, p. 131-136, 2020.

CAMARGO JR, K. R. Medicalização, farmacologização e imperialismo sanitário. Cadernos de Saúde Pública, Rio de Janeiro, v. 29, n. 5, p. 844-846, maio, 2013.

CAPONI, S. Necropolítica e sofrimento psíquico em tempos de pandemia. Mad in Brasil. ciência, psiquiatria e justiça social, 15 agosto 2020. Disponível em: <https://madinbrasil.org/2020/08/necropolitica-e-sofrimento-psiquico-em-tempos-de-pandemia>. Acesso em: 18 ago. 2020.

CASARA, R. R. R. (Org.). Em tempos de pós-democracia. Florianópolis: Tirant Brasil, 2018.

CAVALLINI, M. Medidas do governo durante a pandemia mudam a vida do trabalhador; veja lista. G1, Rio de Janeiro, 21 de abril de 2020. Disponível em: <https://g1.globo.com/economia/noticia/ 2020/04/21/medidas-do-governo-durante-a-pandemia-mudam-avida-do-trabalhador-veja-lista.ghtml>. Acesso em: 05 set. 2020.

CURIEL, O. Ochy Curiel e o feminismo decolonial. [Entrevista concedida a] Ana Paula Procópio da Silva, Magali da Silva Almeida e Renata Gonçalves. Em Pauta: teoria social e realidade contemporânea - Revista da FSS/UERJ. Rio de Janeiro, n. 46, v. 18, p. 269-277, jul./dez., 2020. Disponível em: <https://www.e-publicacoes.uerj.br/ index.php/revistaempauta/article/view/52020/34475>. Acesso em: 11 set. 2020.

DENTICO. N. A perigosa corrida às vacinas dos nacionalismos. Tradução de Luisa Rabolini. Instituto Humanitas Unisinos - IHU, 11 de setembro 2020. Disponível em: <http://www.ihu.unisinos.br/78-noticias/602770-a-perigosa-corrida-as-vacinas-dos-nacionalismos>. Acesso em: 11 set. 2020. 
DORNELLES, J. R. Necrocapitalismo e neofascismo em tempos de peste. In: AUGUSTO, C. B.; SANTOS, R. D. dos. (Org.). Pandemias e pandemônio no Brasil. São Paulo: Tirant lo Blanch, 2020.

DUARTE, M. J. de O.; TOMAZ, M.; CAPUTO, L. R.; BEDIM, V. B. A saúde mental em tempos de desafios e retrocessos: uma revisão. Argumentum, Vitória, v. 12, n. 2, p. 91-106, 2020. Disponível em:

<https://periodicos.ufes.br/argumentum/article/view/29203>. Acesso em: 06 set. 2020.

.; MENEGAT, E. M.; FERREIRA, V. de F. Os novos manicômios a céu aberto: cidade, racismo e loucura. Em Pauta: teoria social e realidade contemporânea - Revista da FSS/UERJ., Rio de Janeiro, n. 45, v. 18, p. 100-115, 10 semestre de 2020. Disponível em: <https://www.epublicacoes.uerj.br/index.php/revistaempauta/article/view/ 47217/31982>. Acesso em: 10 set. 2020.

. Política de saúde mental e drogas: desafios ao trabalho profissional em tempos de resistência. Libertas, Juiz de Fora, v. 18, n. 2, p. 227-243, jul./dez. 2018. Disponível em: < https:// periodicos.ufjf.br/index.php/libertas/article/view/18604/9730>. Acesso em: 01 set. 2020.

FERREIRA, L.; LEÃO, N.; FERRARI, M. Metade das mulheres brasileiras passou a cuidar de alguém durante a pandemia. Gênero e número, Rio de Janeiro, 30 jul. 2020. Disponível em: <http://www.generonumero.media/metade-mulheres-passou-cuidar-pandemia/>. Acesso em: 06 set. 2020.

FONSECA, E. M.; BASTOS, F. I. Os tratados internacionais antidrogas e o Brasil: políticas, desafios e perspectivas. In: ALARCON, S.; JORGE, M. A. S. (Org.) Álcool e outras drogas: diálogos sobre um mal-estar contemporâneo. Rio de Janeiro: Editora Fiocruz, 2012.

FOUCAULT, M. Nascimento da biopolítica. São Paulo: Martins Fontes, 2008a. tes, 2008b.

Seguridade, território e população. São Paulo: Martins Fon. Em defesa da sociedade. São Paulo: Martins Fontes, 2005. 
GOOGLE NOTÍCIAS. Coronavírus (COVID-19). Disponível em: <https://news.google.com/covid19/map?hl=pt-BR\&mid=\%2Fm \%2F01hd4s\&gl=BR\&ceid=BR\%3Apt-419>. Aceso em: 10 set. 2020.

GUIMARÃES, T. de A. A.; ROSA, L. C. dos S. A remanicomialização do cuidado em saúde mental no Brasil no período de 2010-2019: análise de uma conjuntura antirreformista. O Social em Questão, Rio de Janeiro, Ano XXII, n. 44, p. 111 - 138, mai./ago., 2019. Disponível em: <http://osocialemquestao.ser.puc-rio.br/media/OSQ_44_art5.pdf>. Acesso em: 02 set. 2020.

HARVEY, D. Política anticapitalista em tempos de COVID-19. In: DAVIS, M. et al. Coronavírus e a luta de classes. Terra sem Amos: Brasil, 2020a.

. David Harvey: Política anticapitalista em tempos de coronavírus. Blog da Boitempo, São Paulo, 24 mar. 2020b. Disponível em <https://blogdaboitempo.com.br/2020/03/24/david-harvey-politicaanticapitalista-em-tempos-de-coronavirus/>. Acesso em: 19 ago. 2020.

INSTITUTO BRASILEIRO DE GEOGRAFIA E ESTATístICA - IBGE. Pesquisa de Orçamentos Familiares - POF 2017-2018. Rio de Janeiro: IBGE, 2019.

\section{. Pesquisa Nacional por Amostra de Domicílios Contínua -} PNAD Contínua. Rio de Janeiro: IBGE, 2020.

INTERNATIONAL LABOR ORGANIZATION - ILO. ILO Monitor: COVID-19 and the world of work. Fifth edition Updated estimates and analysis. Genebra: ILO, 2020.

LEMOS, F. C. S. et al. O extermínio de jovens negros pobres no Brasil: práticas biopolíticas em questão. Pesquisas e Práticas Psicossociais, São João del Rei, v.12, n. 1, jan./abril, 2017. Disponível em: <http:// seer.ufsj.edu.br/index.php/revista_ppp/article/view/1912/1285>. Acesso em: 10 ago. 2020.

MACHADO, L. Funcionários das áreas de segurança e limpeza do HC de SP foram sete vezes mais infectados do que médicos de UTI de COVID. G1, São Paulo, 04 de setembro de 2020. Disponível em: 
<https://g1.globo.com/sp/sao-paulo/noticia/2020/09/04/funcionarios-das-areas-de-seguranca-e-limpeza-do-hc-de-sp-foram-7-vezesmais-infectados-do-que-medicos-de-uti-de-covid.ghtml>. Acesso em: 04 set. 2020.

MARQUES, E. S. et al. A violência contra mulheres, crianças e adolescentes em tempos de pandemia pela COVID-19: panorama, motivações e formas de enfrentamento. In: Cadernos de Saúde Pública, Rio de Janeiro, v. 36, n. 4, e00074420, 2020. Disponível em: <https:// www.scielo.br/scielo.php?script=sci_arttext\&pid=S0102311X2020000400505\&lng=en\&nrm=iso>. Acesso em: 06 set. 2020.

MBEMBE, A. Necropolítica: biopoder, soberania, estado de exceção, política de morte. São Paulo: n-1 editora, 2018.

MEDEIROS, R. S. Coexistir no espaço-tempo da pandemia. Revista Ensaios de Geografia, Niterói, vol. 5, n. 9, p. 142-147, maio, 2020. Disponível em: <https://periodicos.uff.br/ensaios_posgeo/article/view/ 42304/pdf>. Acesso em: 08 set. 2020.

OLIVEIRA, N. Desigualdade e abusos na pandemia impulsionam cobranças por direitos humanos. Agência Senado, Brasília, 28 de agosto de 2020. Disponível em: <https://www12.senado.leg.br/noticias/infomaterias/2020/08/desigualdade-e-abusos-na-pandemia-impulsionam-cobrancas-por-direitos-humanos>. Acesso em: 05 set. 2020.

PAULO, P. P.; SANTIAGO, T. Quem trabalha fora de casa tem o triplo de chance de se infectar por COVID-19, diz pesquisa da Prefeitura de SP. G1, São Paulo, 13 de agosto de 2020. Disponível em: <https:// g1.globo.com/sp/sao-paulo/noticia/2020/08/13/pesquisa-da-prefeitura-de-sp-mostra-que-quem-trabalha-fora-de-casa-tem-tres-vezesmais-chance-de-se-infectar-por-covid-19.ghtml>. Acesso em: 05 set. 2020.

RODRIGUES, A. Mortes por COVID-19 têm mais relação com autônomos, donas de casa e transporte público. Folha de São Paulo, São Paulo, 09 de agosto de 2020. Disponível em: <https://www1.foIha.uol.com.br/equilibrioesaude/2020/08/mortes-por-covid-19-temmais-relacao-com-autonomos-donas-de-casa-e-transporte-publico.shtml>. Acesso em: 05 set. 2020. 
RONAN, G. Pretos e pardos têm mais chances de morrer por COVID19 que brancos em BH. Estado de Minas, Belo Horizonte, 23 de junho de 2020. Disponível em: <https://www.em.com.br/app/noticia/gerais/2020/07/23/interna_gerais,1169602/covid-19-60-dos-moradores-de-bh-que-morreram-eram-pretos-ou-pardos.shtml>. Acesso em: 03 set. 2020.

SANTOS, H. L. P. C. et al. Necropolítica e reflexões acerca da população negra no contexto da pandemia da COVID-19 no Brasil: uma revisão bibliográfica. Ciência \& Saúde Coletiva, Rio de Janeiro [periódico na internet], agosto, 2020. Disponível em: <http://www.cienciaesaudecoletiva.com.br/artigos/necropolitica-e-reflexoes-acerca-da-populacao-negra-no-contexto-da-pandemia-da-covid19-no-brasil-umarevisao-bibliografica/17719?id=17719>. Acesso em: 06 set. 2020.

SIMONI, C. A COVID-19 e o direito à cidade aos pobres no Brasil. In: CARLOS, A. F. A. (Org.). COVID-19 e a crise urbana [recurso eletrônico]. São Paulo: FFLCH/USP, 2020.

SUTTO, G. Auxílio emergencial deve custar 13 anos de Bolsa Família no total; entenda a nova fase do programa. InfoMoney, São Paulo, 5 de setembro de 2020. Disponível em: <https://www.infomoney.com.$\mathrm{br} / \mathrm{minhas}$-financas/auxilio-emergencial-deve-custar-13-anos-debolsa-familia-no-total-entenda-a-nova-fase-do-programa/>. Acesso em: 05 set. 2020

VOLOCHKO, D. O cotidiano dos pobres não pode parar: a pandemia e a necrodemografia do capital. In: CARLOS, A. F. A. (Org.). COVID-19 e a crise urbana [recurso eletrônico]. São Paulo: FFLCH/USP, 2020. WORLD HEALTH ORGANIZATION - WHO. Transmission of SARS-CoV2: implications for infection prevention precautions: scientific brief, 09 July 2020. Disponível em: <https://apps.who.int/iris/handle/ 10665/333114>. Acesso em: 10 set.2020. 